Int. J. Dev. Biol. 53: 425-432 (2009)

doi: $10.1387 / \mathrm{ijdb} .082687 \mathrm{jg}$

\title{
Genome reprogramming during sporulation
}

\author{
JEROME GOVIN and SHELLEY L. BERGER* \\ Gene Expression and Regulation Program, The Wistar Institute, Philadelphia, USA
}

\begin{abstract}
When environmental conditions compromise survival, single celled organisms, such as the budding yeast $S$. cerevisiae, induce and complete a differentiation program called sporulation. The first step consists of meiosis, which generates genetic diversity within the eventual haploid cells. The post-meiotic maturation stage reinforces protective barriers, such as the spore wall, against deleterious external conditions. In later stages of sporulation, the spore nucleus becomes highly compacted, likely sharing certain characteristics with the metazoan male gamete, the spermatozoon. The sporulation differentiation program involves many chromatinrelated events, including execution of a precise transcription program involving more than one thousand genes. Here, we review how chromatin structure and genome reprogramming regulate the sporulation transcription program, and how post-meiotic events reorganize spore chromatin.
\end{abstract}

KEY WORDS: sporulation, chromatin, compaction, reproduction, development

Unicellular vegetal and fungal organisms have a restricted choice of growth adaptations to respond to dramatic changes in their environment. Upon nutrient limitation, the budding yeast Saccharomyces cerevisiae can switch to a pseudohyphal-type growth, which is characterized by several morphological changes, including invasion of a solid growth media and filamentous growth (Gancedo, 2001). Pseudohyphal growth can be induced by nitrogen limitation, by poor carbon sources such as lactate, or by some organic compounds (Gimeno et al., 1992; Zaragoza and Gancedo, 2000). Pseudohyphal invasion probably reflects the search for nutrients, and escape from a potentially harmful environment (Gimeno et al., 1992; Zaragoza and Gancedo, 2000).

Complete nutrient depletion induces another response, which varies in haploid and diploid yeast. Haploid yeast enter a nonmetabolic and quiescent phase, called G0. Diploid yeast undergo a differentiation pathway called sporulation. During sporulation, meiosis generates haploid daughter cells, which then differentiate into stress-resistant spores. In diploid yeast, the choice between pseudohyphal-type growth and sporulation is regulated by the relative abundance of two RNA polymerase II subunits, Rpb4 and Rpb7 (Singh et al., 2007). Rpb4 enhances sporulation efficiency and represses pseudohyphae formation, while Rpb7 acts in reverse (Singh et al., 2007).

Shortly following initiation of sporulation, diploid yeast go through meiosis (Fig. 1). Meiosis has a central role in the sexual reproduction in nearly all eukaryotes, and is critical for generating genetic diversity while conserving a functional genome (Marston and Amon, 2004). The first division deviates from mitotic cell division, in having a prolonged DNA replication phase to allow homologous pairing and recombination during an extended prophase, and disjunction of homologues. In contrast, the second division is similar to mitosis, in that it is short, and it uses the same machinery to disjoin the previously replicated sister chromatids.

The second major event of sporulation is the post-meiotic maturation of spores, when the haploid genome is compacted and protected by the spore wall. This wall is able to ensure spore survival over long times, and protects genome integrity from severe damage induced by chemical or physical stress (Neiman, 2005).

Two main events effect genome programming during sporulation. The first event is execution of a precise transcription program. Upon nitrogen and glucose starvation, the master regulator Ime1 is expressed and induces the expression of early genes encoding the first proteins needed for meiotic $S$ phase (Fig. 1). Secondly, the genome is reorganized during the post meiotic portion of sporulation. During this time haploid spores compact their nucleus, implying a dramatic reorganization of the chromatin structure, including chromatin compaction and germination preprogramming.

\footnotetext{
Abbreviations used in this paper:HAT, histone acetyltransferase; HDAC, histone deacetylase; MSE, middle sporulation element; UAS, upstream activation sequence; UCS, upstream control sequence; URS, upstream repression sequence.
}

\footnotetext{
*Address correspondence to: Shelley L. Berger. The Wistar Institute, 3601 Spruce Street, Philadelphia PA19104. Fax: +1-215-898-0663. e-mail: berger@wistar.org - web: http://www.wistar.org/research_facilities/berger/research.htm
} 
Several detailed reviews describe transcriptional regulation during sporulation (for more details please refer to Kassir et al., 2003; Kupiec et al., 1997), therefore, we will only briefly review transcription, and instead, focus on genome reprogramming.

\section{The transcription cascade during sporulation}

Approximately 1000 genes are specifically expressed during sporulation (Chu et al., 1998; Primig et al., 2000). Three main groups of genes can be distinguished, called early, middle and late sporulation genes (Chu et al., 1998). However, a more precise evaluation of transcript abundance and timing of expression defines up to 10 clusters of genes (Primig et al., 2000). Each cluster of genes is repressed during vegetative growth and sporulation, except during a limited period of activation.

The early genes are involved in the earliest meiotic events, including meiotic replication, recombination, synaptonemal complex formation, sister chromatid and centromere cohesion during the first prophase. Their induction is controlled by the master inducer Ime1 (Fig. 1).

Middle genes are expressed when cells initiate the first meiotic division. They function mainly in the pachytene checkpoint, including several B-type cyclins, anaphase promoting complex proteins and others factors involved in cell division during meiotic $M$ phase (Primig et al., 2000). The principal regulator of mid-sporulation is Ndt80, which autoactivates its own expression and induces middle gene expression (see Fig 2., Chu and Herskowitz, 1998; Pierce et al., 2003). Late genes are involved in post-meiotic differentiation, and encode proteins required for spore wall maturation.

The timing of gene expression correlates strongly with sporulation functions. Thus, clusters designating unknown genes have been used to provide clues to function, e.g. SPO22 and SPO19 are assigned to meiosis based on their expression pattern (Primig et al., 2000).

\section{Repression of sporulation during vegetative growth}

Diploid yeast must constantly repress sporulation, unless justified by poor environmental conditions. Indeed, initiation of the sporulation program precludes vegetative growth for 24 hours, i.e. for the equivalent of twelve divisions. In other words, a single cell creates four new spores, while several thousand daughter cells might have been generated during the same period. Therefore, sporulation firing is efficiently repressed during vegetative growth and finely controlled under nutrient deprivation. Moreover yeast undergoing early stages of meiosis may return to vegetative growth if nutrients are provided. However, if yeast reach a certain stage of sporulation, they become "committed to sporulate" (Simchen et al., 1972). Commitment occurs after premeiotic DNA replication and recombination, but before meiosis I (Fig. 1). The sporulation process involves critical changes in cell morphology, chromatin structure and cell-wall composition, which may be lethal if abandoned mid-course. Indeed, in the presence of new nutrients, committed cells repress any activation of mitogenic signals to ensure completion of the sporulation program (Friedlander et al., 2006).

\section{Sporulation repression in haploid cells}

Repression of sporulation is fundamental to haploid growth, in order to maintain a functional genome. Indeed, ectopic induction of sporulation leads to inappropriate meiosis and production of non-viable cells.

The protein Rme1 represses sporulation in haploid yeast, but also in artificially created diploids that are not appropriate mating types, i.e. MATa/MATa diploids (see Fig. 2B, Kassir and Simchen, 1976). Rme1 inhibits the expression of the master regulator of sporulation, Ime1 (Covitz and Mitchell, 1993). Rme1 binds to two regulatory elements of the IME1 promoter, named Upstream Control Regions 3 and 4 (UCS3, UCS4, see Fig. 2B and 3; Shimizu et al., 1998). As a repressor, Rme1 modifies the chromatin structure of the IME1 promoter to prevent the binding of activators. Further, Rme1 recruits Sin4 and Rgr1, which likely modify IME1 promoter chromatin structure in a repressive manner (Shimizu et al., 1997).

\section{Repression of sporulation induced genes during vegeta- tive growth}

During vegetative growth, several repressive mechanisms prevent the expression of the sporulation-specific genes. Interestingly, these repression mechanisms differ for early compared to middle genes. Several early genes are repressed by Ume6 (Fig. 2A), which is a C6 zinc cluster DNA binding protein that binds to an Upstream Repression Sequence 1 (URS1) present in the promoter of numerous early genes (Anderson et al., 1995; Strich et al., 1994). Deletion of UME6 induces the 
expression of early genes as well as non-meiotic genes carrying the URS1 elements in vegetative growth conditions (Bowdish and Mitchell, 1993; Strich et al., 1994). Ume6 interacts with Sin3, which in turn recruits the histone deacetylase Rpd3 to early genes promoters (Fig. 2A, Kadosh and Struhl, 1997). Histone deacetylases (HDAC) are well known repressors of transcription, and are present in key repressor complexes.

Ume6 also recruits Isw2, an ATP-dependant chromatin-remodeling factor. Isw2 recruitment is required for repression of early genes during vegetative growth (Goldmark et al., 2000). Isw2 likely establishes and maintains compact chromatin structure at early gene promoters (Goldmark et al., 2000).

In contrast, middle genes are repressed in haploid and diploid cells by Sum1 (Fig. 2A). More than 50 genes are directly repressed by Sum1 during vegetative growth (Pierce et al., 2003). Sum1 specifically recognizes the Middle Sporulation Element (MSE), a DNA region known to regulate the middle gene class (Pierce et al., 2003; Xie et al., 1999). Sum 1 action involves the $\mathrm{NAD}^{+}$dependant histone deacetylase Hst1, which is closely related to Sir2. The Sum1-Hst1 interaction is mediated by Rfm1, indispensable to Sum1 mediated repression (McCord et al., 2003).

Much less is known about late gene repression. The repressor complex Tup1/Ssn6 is involved in the repression of several sporulation genes, including the late genes DIT1 and DIT2 (Fig. 2A), but also the early gene IME1 (Friesen et al., 1997; Mizuno et al., 1998). Tup1/Ssn6 also recruits HDAC activity as a repression mechanism (for review see Malave and Dent, 2006).

\section{The master sporulation-inducer Ime1}

As mentioned above, repression vs. induction of the sporulation program in diploid cells is mainly regulated by nutrient availability. Yeast sense several nutrients, including the quality of the nitrogen or carbon source, but also the presence of phosphate, sulfate, nucleotides and amino acids (Freese et al., 1982; Varma et al., 1985).

Ime1 is believed to be the main inducer of sporulation. IME1 null mutations prevent detectable expression of all meiotic genes that have been examined, with the exception of IME4 (see below and for review Kassir et al., 2003; Kupiec et al., 1997). The IME1 promoter is large $(2.1 \mathrm{~kb})$ compared to that of most genes (200-300 bp) in S. cerevisiae, and consists of both positive and negative elements (See Fig. 3; Sagee et al., 1998). It is divided into four Upstream Controlling regions, named UCS1 to UCS4 (Fig. 3). UCS2 is itself divided into seven elements: three Upstream Activation Sequences (UASv, UASrm and UASru), two Upstream Repression Sequence (URSd and URSu), and two IRE elements (IREd and IREu). Together, these 10 DNA regions control IME1 transcription, by integrating signals of the cell ploidy state, and abundance of carbon and nitrogen.

\section{Ploidy sensor pathway}

The MAT pathway is a sensor of ploidy and mating type. Diploid MATa/MAT $\alpha$ yeast express MATa1 and MAT $\alpha 2$ genes, whose
A

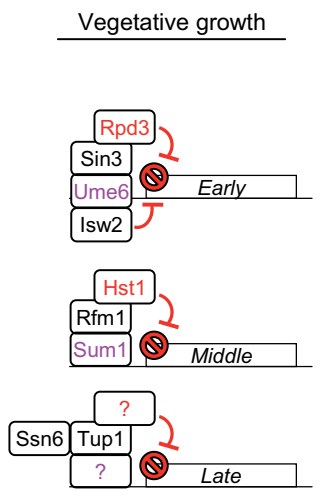

Sporulation
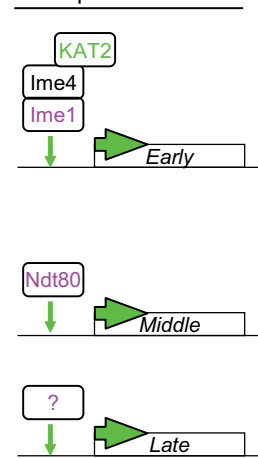

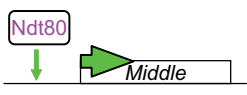

B

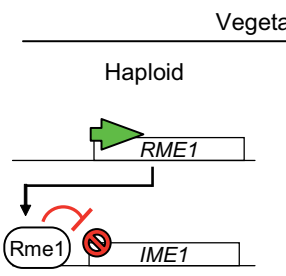

Vegetative growth

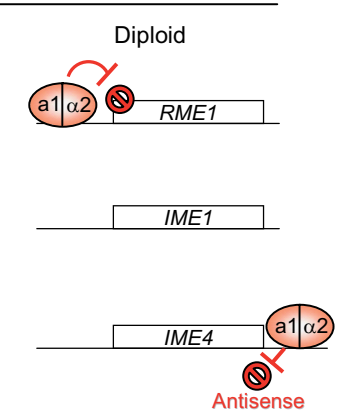

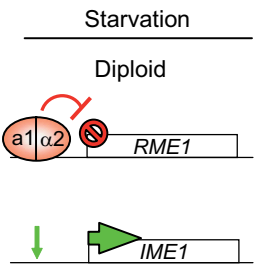

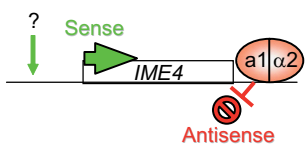

Fig. 2. Transcription regulation during sporulation. (A) Regulation of early, middle and late gene expression. During vegetative growth, the transcriptional repressor Ume6 recognizes a specific sequence in early gene promoters and recruits several complexes essential for their repression. These co-repressors notably include the histone deacetylase Rpd3 and the ATP-dependant remodeling enzyme Isw2. Upon sporulation, Ime 1 is responsible for the transcription of early genes. Ime4 and the histone acetyltransferase KAT2/Gcn5 are required for their proper activation. Middle genes are repressed by Sum 1, which recruits Rfm1 and the histone deacetylase Hst1. Ntd80 is the main activator of early gene expression during sporulation. Late gene regulation is less clear; repression may involve the co-repressors Ssn6/Tup1. DNA binding proteins are in purple, histone deacetylases are in red, and the histone acetyltransferase is in green. New enzyme nomenclature has been used (Allis et al., 2007). (B) Regulation of key transcription factors during sporulation. Rme 1 is the main repressor of sporulation in haploid yeast. It recognizes specific elements in the IME1 promoter and prevents Ime1 expression. In diploid yeast, the product of the mating type genes MATa1/MAT 2 form a heterodimer, which binds to the RME1 promoter and prevents Rme1 expression. In diploid cells, IME1 is derepressed in vegetative growth conditions and activated upon nutrient starvation. The IME4 gene is regulated by competition between a sense and an antisense transcript (Hongay et al., 2006). The antisense promoter is stronger than the sense one, and antisense transcription inhibits the expression of IME4 in cis in haploid yeast. In diploid yeast, the a1/ 22 heterodimer binds an element downstream of the IME4 gene and prevents antisense transcription. During vegetative growth, IME4 is derepressed and activated at the beginning of sporulation. 
products form a heterodimer called a1- $\alpha 2$ (Herskowitz et al., 1992). The a1- $\alpha 2$ heterodimer binds to an operator site in the $R M E 1$ promoter and represses transcription (Fig. 2B, Covitz et al., 1991). The absence of Rme1 derepresses IME1 transcription, allowing sporulation induction upon starvation. Therefore, the presence of this heterodimer is absolutely required for sporulation induction, preventing sporulation in haploid cells, in which meiosis would lead to severe chromosomal abnormalities.

\section{Nutrient sensor pathway}

A second pathway regulates sporulation induction, and is based on the nutritional environment. The IME1 promoter contains several elements sensitive to nitrogen levels and to the type of carbon source, such as glucose or acetate (Fig. 3).

One repressive element is UCS1 in the IME1 promoter, which responds to nitrogen levels; depletion of UCS1 leads to inappropriate derepression of IME1 during vegetative growth. In addition, mutants that lack cAMP or AMP dependant-protein kinase activity (PKA) also sporulate in the absence of nitrogen limitation (Matsumoto et al., 1983). The kinase Cdc25, a known PKA and MAP-kinase activator, may transmit the nitrogen signal to UCS1, as repression activity of UCS1 is reduced if $C D C 25$ is mutated (Matsumoto et al., 1983).

The type of carbon source also regulates sporulation. Glucose represses sporulation, and non-fermentable carbon sources, such as acetate, induce sporulation. The IME1 promoter senses glucose through UCS2. Three main elements, UASru, UASrm and IREu, repress in the presence of glucose, but activate in the absence of glucose and/or the presence of acetate (Kassir et al., 2003). The positive and negative signaling pathways also likely use the cAMP/PKA pathway (for more details, please refer to Kassir et al., 2003).

To conclude, 10 distinct elements in combinatorial fashion provide the appropriate IME1 expression pattern (Fig. 3). The elements UCS1, IREu, UASru and UASv integrate several signaling pathways to repress IME1 transcription in the presence of glucose. In the presence of acetate media, IME1 is expressed at low levels, resulting from the competition of the repressive action of UCS1, URSu, URSd, IREd and the positive action of UASru,
IREu, UASrm and UASv. Upon nitrogen depletion, relief of UCS1 repression promotes the increase of transcription (Kassir et al., 2003).

\section{IME1 promoter chromatin structure}

Despite the abundance of information on the distinct DNA elements of the IME1 promoter, and their binding proteins, it is striking that its chromatin structure in repressed or activated states remains uncharacterized. Indeed, chromatin packaging regulates gene access and function during transcription (Li et al., 2007). The chromatin building module, the nucleosome, masks or reveals regulatory DNA sequences to binding proteins. The organization of the chromatin at higher levels also regulates genome accessibility. Thus it is likely that chromatin dynamics regulate the sporulation transcription program.

Histone $\mathrm{H} 2 \mathrm{~A}$ and $\mathrm{H} 2 \mathrm{~B}$ abundance regulates IME1 expression. Sporulation defects occur in strains where expression of $\mathrm{H} 2 \mathrm{~A}$ / H2B-encoding genes is reduced (Norris and Osley, 1987; Tsui et al., 1997). The limited amount of H2A/H2B lowers IME1 expression, preventing proper regulation of the transcription cascade and the sporulation program, likely because of perturbation of the fine organization of the IME1 promoter, rather than by a dramatic change in nucleosome distribution (Hanlon et al., 2003).

We note that most of these data have been generated using a reporter gene under the control of different parts of IME1 promoter (Kassir et al., 2003). Despite the technical convenience of this approach, it remains questionable whether these DNA constructs reproduce the chromatin state of the endogenous IME1 promoter. Study of the chromatin structure of the normal IME1 promoter during sporulation repression and induction may reveal new aspects of its regulation, and explain its sensitivity to $\mathrm{H} 2 \mathrm{~A} / \mathrm{H} 2 \mathrm{~B}$ abundance.

Histone variants also modulate transcription (Li et al., 2007). Some sporulation specific genes, such as DIT1 and DIT2, are enriched in H2A.Z during vegetative growth (Raisner et al., 2005). This $\mathrm{H} 2 \mathrm{~A}$ variant is incorporated into the 5' region of active or inactive genes (Raisner et al., 2005), poising them for rapid induction of transcription (Zhang et al., 2005). Moreover, DIT1

Fig. 3. Inducer of meiosis 1 (IME1) promoter regulation. The IME1 promoter is divided in four Upstream Control Regions, UCS1-4. UCS3 and UCS4 respond to a ploidy control pathway, which prevents sporulation in haploid yeasts. UCS1 responds to nitrogen abundance, and has a repressive effect on IME1 transcription. UCS2 responds to the type of carbon source. Glucose represses IME1 transcription via the DNA elements UASV, IREu and UASru, whereas acetate activates IME1 transcrip-
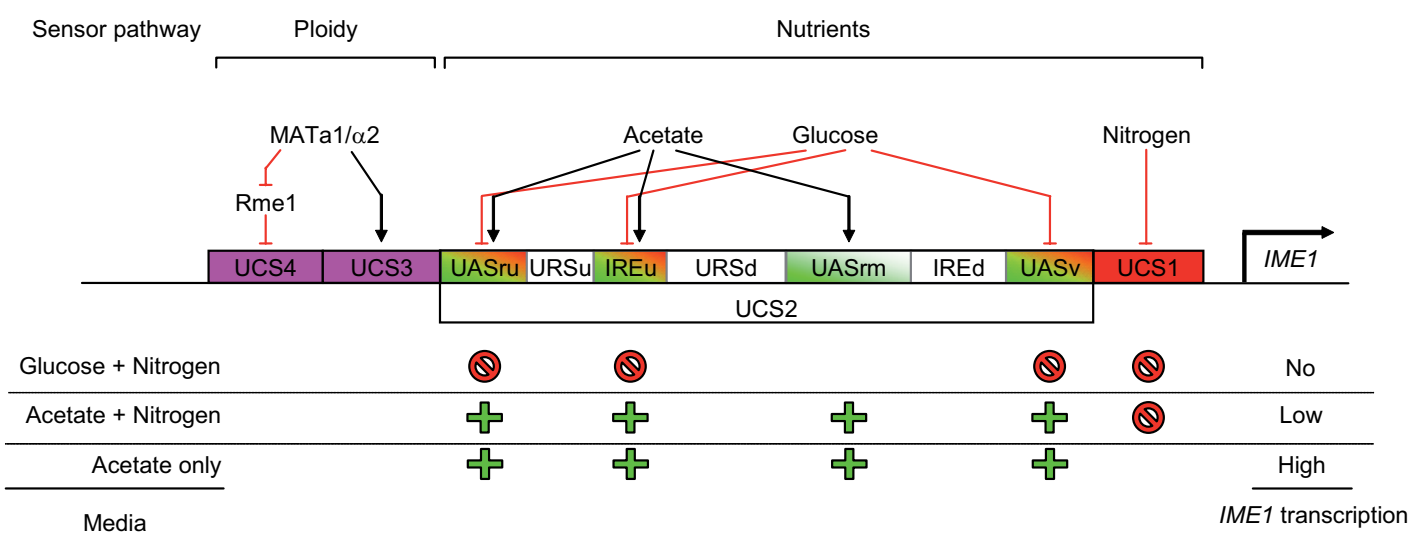
tion via UASrm, IREu and UASru.

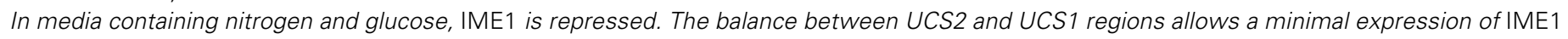

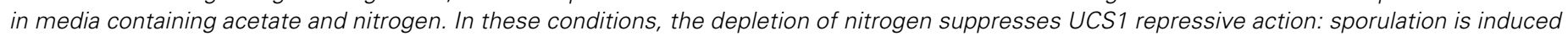

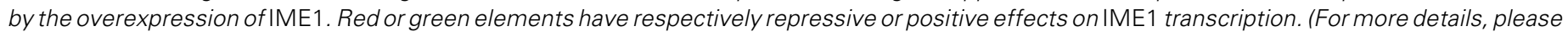
refer to text, Kassir et al., 2003; Kupiec et al., 1997). 


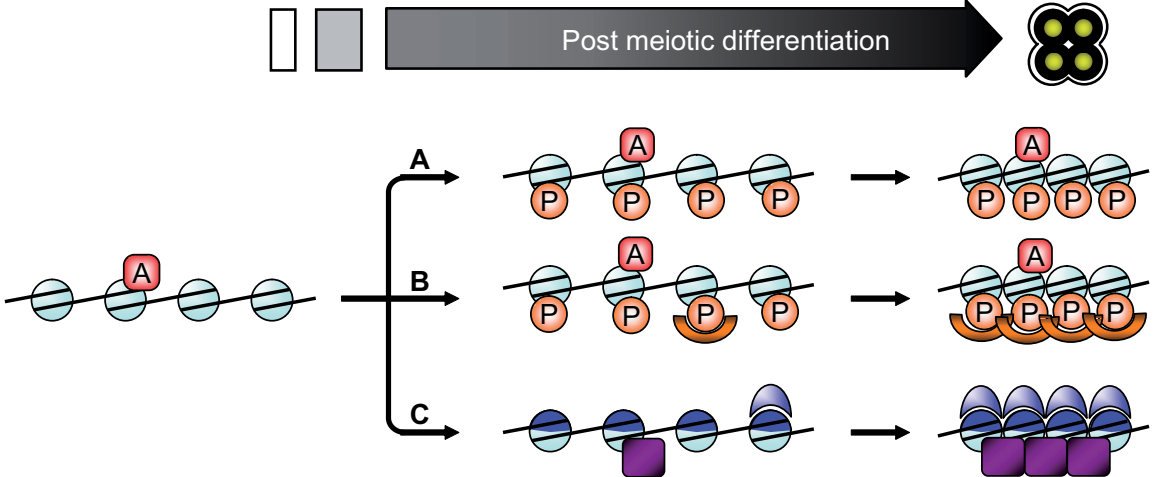

and DIT2 are repressed by Tup1/Ssn6, which promotes incorporation of $\mathrm{H} 2 \mathrm{~A} . \mathrm{Z}$ during repression of the GAL1 gene (Gligoris et al., 2007). Tup1/Ssn6 is also involved in the repression of IME1 (Mizuno et al., 1998). Two regions present in UCS2 of the IME1 promoter mediate Tup1/Ssn6 action, but the specific targeting DNA-binding protein is not known (Mizuno et al., 1998). Therefore, Tup1/Ssn6 repression of IME1 could lead to incorporation of $\mathrm{H} 2 \mathrm{~A}$.Z, to facilitate rapid transcription activation upon nutrient starvation.

\section{IME4 antisense transcription controls sporulation in- duction}

IME4 is the only sporulation gene whose expression does not depend on Ime1. The mechanism of Ime4 transcription regulation has been revealed recently (Hongay et al., 2006), and occurs through a fine balance of sense and antisense transcription (Fig. $2 \mathrm{~B}$ ), expression of which are mutually exclusive. The default transcript is the antisense, as its promoter is stronger than the sense promoter. Therefore haploid yeasts generously express the antisense transcript and do not express Ime4 protein. In diploid cells, the a1/ $\alpha 2$ heterodimer binds a consensus motif located downstream of IME4 ORF, and blocks antisense transcription (Fig. 2B). Thus, under nitrogen starvation, IME4 sense transcription can be induced (Hongay et al., 2006). This mechanism uncovers a new way of controlling cell fate in $S$. cerevisiae, since numerous antisense RNAs have been identified but not associated with function (David et al., 2006; Samanta et al., 2006).

\section{Activation of sporulation-induced genes}

\section{Early gene activation}

Early genes are mainly repressed by the HDAC complex Sin3/ Rpd3 and the remodeling complex Isw2 (see previous section). Isw2 modifies nucleosome positions to establish a nucleaseinaccessible chromatin structure, masking the TATA box for binding (Goldmark et al., 2000). Upon activation, Ime1 recognizes an Upstream Regulation Sequence, URS1, and recruits the remodeling complex $\mathrm{RSC}$, which alters the repressive chromatin structure (Inai et al., 2007). RSC specifically counteracts the Isw2-induced structure, since RSC activity is dispensable for IME2 activation in the absence of Isw2.
Fig. 4. Chromatin compaction in spores. A model is presented to describe potential mechanisms leading to compaction of chromatin in mature spores. The phosphorylation of serine 1 of histone $\mathrm{H} 4$ has been described as a key factor of chromatin compaction (Krishnamoorthy et al., 2006). This modification may directly promote chromatin compaction (A), possibly counteracting other 'decompaction' marks (which may persist as epigenetic modifications to specify genes in the next generation of vegetative cells). Certain proteins may recognize H4S1ph to promote chromatin compaction (B). Finally, chromatin composition itself may be modified by incorporation of chromatin proteins, such as histone variants (dark blue). These new elements may directly promote chromatin compaction, or may recruit other factors which would achieve the final compaction (C).
Efficient activation of early and middle genes transcription requires Gcn5/KAT2, a histone acetyltransferase (HAT) (Fig. 2A, Burgess et al., 1999). However, the kinetics of histone acetylation on the IME2 promoter is not related to its transcription activation (Inai et al., 2007). Acetylation of histones at IME2 promoter accumulates when a non-fermentable carbon source such as acetate is available, but before the gene is actually transcribed (Inai et al., 2007). Therefore acetylation might change higher chromatin structure to facilitate future binding of Ime1, without altering nucleosome positioning and IME2 repression.

\section{Destruction of Ume6 repressor promotes meiotic gene in- duction}

Ume6 function during induction of sporulation has remained mysterious, as this strong repressor of sporulation during vegetative growth (via HDAC recruitment) is also required for sporulation induction (Bowdish et al., 1995). It has been recently shown that Ume6 is rapidly degraded during sporulation induction, and that this degradation is required for the normal expression of early and middle genes, and destruction requires brief interaction with Ime1 (Mallory et al., 2007). Thus, Ume6 destruction disrupts HDACmediated repression (Mallory et al., 2007) to enhance Gcn5dependent acetylation and promote early and middle gene transcription.

\section{Middle and late genes}

Middle and late gene activation are not well understood. Ndt80 is responsible for middle gene activation, by recognition of a specific DNA sequence, the Middle Sporulation Element (MSE). The transcription factor responsible for late gene induction is unknown. However, similar to early genes, the RSC chromatin remodeling complex is required for the full expression expression of late genes, and formation of fully mature spores (Bungard et al., 2004).

Currently nothing is known about a role of histone variants during sporulation. It will be be interesting to determine whether $\mathrm{H} 2 \mathrm{~A}$. $\mathrm{Z}$ is involved in the activation of sporulation-induced genes.

\section{Post meiotic genome reorganization and compaction}

During post-meiosis, newly haploid spores differentiate into fully mature spores, which will protect them from adverse physical and chemical environmental conditions. This process involves 
the expression of the late genes, which are mainly involved in spore wall maturation (Neiman, 2005).

The nuclear volume decreases and chromatin is compacted during post meiotic differentiation, but the mechanisms involved remain to be fully elucidated. Phosphorylation of histone $\mathrm{H} 4$ serine 1 (H4S1ph) appears to be a key mark of this process. $\mathrm{H} 4 \mathrm{~S} 1 \mathrm{ph}$ is absent during meiosis, but accumulates dramatically as spores mature (Krishnamoorthy et al., 2006). Moreover, substitution of serine 1 to alanine, which prevents its phosphorylation, leads to increase of nuclear volume, suggesting that H4S1ph is important in chromatin compaction (Krishnamoorthy et al., 2006). It remains to be determined whether $\mathrm{H} 4 \mathrm{~S} 1 \mathrm{ph}$ acts directly to alter structure. The amino terminal tail extension of $\mathrm{H} 4$ is involved in chromatin structure, and interacts with neighboring nucleosomes (Dorigo et al., 2003; Schalch et al., 2005). Moreover, acetylation of H4 Lysine-16 inhibits the formation of higher chromatin structures (Shogren-Knaak et al., 2006). Thus, in an opposite way, H4S1ph may promote chromatin compaction, and counteract 'decompaction' marks (Fig. 4A).

Methylation and acetylation of histones recruits a large diversity of specific proteins, depending on the modified residue (for review see Ruthenburg et al., 2007). Phosphorylation of histones also recruits specific proteins, such as 14-3-3 proteins (Macdonald et al., 2005). In a similar manner, H4S1ph may recruit specific proteins that would promote chromatin compaction (Fig. 4B).

Finally, new proteins may be incorporated into chromatin to promote compaction (Fig. 4C). During spermatogenesis, specific basic proteins, called protamines, replace nearly all histones, and lead to the final packaging of DNA into the sperm head (Balhorn, 2007). This process has long been thought to be restricted to vertebrates, and protamines have been identified in birds, fish, rodents and primates (for review, Balhorn, 2007). However, recent studies demonstrate their existence in insects, where chromatin reorganization during the final stages of spermatogenesis is very similar to mammals (Jayaramaiah Raja and Renkawitz-Pohl, 2005; Rathke et al., 2007). Therefore, chromatin organization and compaction in spores may involve the function of uncharacterized protamine-like proteins, or other proteins.

\section{Chromatin dynamics during germination}

When new nutrients become available, spores resume vegetative growth during germination. However, spore germination can be induced in conditions that do not allow vegetative growth (Granot and Snyder, 1991; Herman and Rine, 1997). Glucose induces the degradation of the spore wall, but is not sufficient to promote bud emergence and mitosis, and, under these conditions spores stop germinating and die rapidly (Granot and Snyder, 1991). This sequence is seen in the induction of a new gene expression program during germination (Joseph-Strauss et al., 2007). Within 5 min of germination a dramatic change in expression of 1000 genes occurs, and half are up- and half are downregulated. During the first two hours of germination, spores respond only to glucose addition, whereas, during the second phase, cells sense other components, such as nitrogen availability. It remains to be determined why initial sensing is only to carbon source availability.

Interestingly, the gene expression pattern is very similar to the general transcription response of yeast cells to glucose and also closely resembles changes in gene expression observed upon exit from stationary phase (Martinez et al., 2004; Radonjic et al., 2005). During stationary phase, RNA polymerase II has been detected at promoters of genes that will be expressed following exit from starvation (Radonjic et al., 2005). In a similar way, we predict that the first genes to be expressed during germination may be in a similar state, that is, loaded with RNA polymerase II, but in a poised state that prevents transcription elongation.

\section{Concluding remarks}

It is now clear that simple organisms, such as yeast, provide genetic models to unravel complex molecular mechanisms involved in each step of the cell cycle. However, despite wide usage of the yeast model, its only defined differentiation program, sporulation, remains poorly understood.

Nevertheless, sporulation induction is a model of choice to study transcriptional regulation during gametogenesis, as more than one thousand genes are synchronously altered in expression. It is also interesting that yeast sporulation follows a sequence of events similar to higher eukaryotic spermatogenesis. In both cases, genetic information is recombined during meiosis, and then compacted and stored in a unique chromatin structure (that is, compared to vegetative or somatic cells) in haploid, highly differentiated cells. Remarkably, spores germinate to restore a fully functional vegetative cell, just as gametes generate an entire new somatic organism. Yeast genetics and biochemistry has been crucial to our understanding of chromatin dynamics during the main steps of the cell cycle-such as transcription, replication, mitosis and double strand break repair - and has helped to reveal conserved mechanisms in higher eukaryotes, in both normal and pathologic contexts. Thus, continued investigation of the yeast differentiation program during sporulation, will unravel new mechanisms underlying higher eukaryotic development, gametogenesis, germinal and stem cell biology.

\section{Acknowledgements}

We thank all the members of the Berger laboratory for valuable discussions. JG is supported by the Excellence Biomedical Program of the "Fondation de la Recherche Médicale Française", and by the Philippe Foundation. Relevant research in SLB laboratory is supported by $\mathrm{NIH}$ grant GM55360.

\section{References}

ALLIS, C.D., BERGER, S.L., COTE, J., DENT, S., JENUWIEN, T., KOUZARIDES, T., PILLUS, L., REINBERG, D., SHI, Y., SHIEKHATTAR, R. et al. (2007). New nomenclature for chromatin-modifying enzymes. Cell 131: 633-636.

ANDERSON, S.F., STEBER, C.M., ESPOSITO, R.E. and COLEMAN, J.E. (1995). UME6, a negative regulator of meiosis in Saccharomyces cerevisiae, contains a C-terminal Zn2Cys6 binuclear cluster that binds the URS1 DNA sequence in a zinc-dependent manner. Protein Sci 4: 1832-1843.

BALHORN, R. (2007). The protamine family of sperm nuclear proteins. Genome Biol 8: 227.

BOWDISH, K.S. and MITCHELL, A.P. (1993). Bipartite structure of an early meiotic upstream activation sequence from Saccharomyces cerevisiae. Mol Cell Biol 13: $2172-2181$.

BOWDISH, K.S., YUAN, H.E. and MITCHELL, A.P. (1995). Positive control of yeast meiotic genes by the negative regulator UME6. Mol Cell Biol 15: 2955-2961.

BUNGARD, D., REED, M. and WINTER, E. (2004). RSC1 and RSC2 are required for expression of mid-late sporulation-specific genes in Saccharomyces 
cerevisiae. Eukaryot Cell 3: 910-918.

BURGESS, S.M., AJIMURA, M. and KLECKNER, N. (1999). GCN5-dependent histone $\mathrm{H} 3$ acetylation and RPD3-dependent histone $\mathrm{H} 4$ deacetylation have distinct, opposing effects on IME2 transcription, during meiosis and during vegetative growth, in budding yeast. Proc Natl Acad Sci U S A 96: 6835-6840.

CHU, S., DERISI, J., EISEN, M., MULHOLLAND, J., BOTSTEIN, D., BROWN, P.O. and HERSKOWITZ, I. (1998). The transcriptional program of sporulation in budding yeast. Science 282: 699-705.

CHU, S. and HERSKOWITZ, I. (1998). Gametogenesis in yeast is regulated by a transcriptional cascade dependent on Ndt80. Mol Cell 1: 685-696.

COVITZ, P.A., HERSKOWITZ, I. and MITCHELL, A.P. (1991). The yeast RME1 gene encodes a putative zinc finger protein that is directly repressed by a1alpha 2. Genes Dev 5: 1982-1989.

COVITZ, P.A. and MITCHELL, A.P. (1993). Repression by the yeast meiotic inhibitor RME1. Genes Dev 7: 1598-1608.

DAVID, L., HUBER, W., GRANOVSKAIA, M., TOEDLING, J., PALM, C.J., BOFKIN, L., JONES, T., DAVIS, R.W. and STEINMETZ, L.M. (2006). A high-resolution map of transcription in the yeast genome. Proc Natl Acad Sci U S A 103: 53205325.

DORIGO, B., SCHALCH, T., BYSTRICKY, K. and RICHMOND, T.J. (2003). Chromatin fiber folding: requirement for the histone $\mathrm{H} 4 \mathrm{~N}$-terminal tail. J Mol Biol 327: 85-96.

FREESE, E.B., CHU, M.I. and FREESE, E. (1982). Initiation of yeast sporulation of partial carbon, nitrogen, or phosphate deprivation. J Bacteriol 149: 840-851.

FRIEDLANDER, G., JOSEPH-STRAUSS, D., CARMI, M., ZENVIRTH, D., SIMCHEN, G. and BARKAI, N. (2006). Modulation of the transcription regulatory program in yeast cells committed to sporulation. Genome Biol 7: R20.

FRIESEN, H., HEPWORTH, S.R. and SEGALL, J. (1997). An Ssn6-Tup1-dependent negative regulatory element controls sporulation-specific expression of DIT1 and DIT2 in Saccharomyces cerevisiae. Mol Cell Biol 17: 123-134.

GANCEDO, J.M. (2001). Control of pseudohyphae formation in Saccharomyces cerevisiae. FEMS Microbiol Rev 25: 107-123.

GIMENO, C.J., LJUNGDAHL, P.O., STYLES, C.A. and FINK, G.R. (1992). Unipolar cell divisions in the yeast $S$. cerevisiae lead to filamentous growth: regulation by starvation and RAS. Cell 68: 1077-1090.

GLIGORIS, T., THIREOS, G. and TZAMARIAS, D. (2007). The Tup1 corepressor directs $\mathrm{Htz1}$ deposition at a specific promoter nucleosome marking the GAL1 gene for rapid activation. Mol Cell Biol 27: 4198-4205.

GOLDMARK, J.P., FAZZIO, T.G., ESTEP, P.W., CHURCH, G.M. and TSUKIYAMA, T. (2000). The Isw2 chromatin remodeling complex represses early meiotic genes upon recruitment by Ume6p. Cell 103: 423-433.

GRANOT, D. and SNYDER, M. (1991). Glucose induces cAMP-independent growth-related changes in stationary-phase cells of Saccharomyces cerevisiae. Proc Natl Acad Sci U S A 88: 5724-5728.

HANLON, S.E., NORRIS, D.N. and VERSHON, A.K. (2003). Depletion of H2A-H2B dimers in Saccharomyces cerevisiae triggers meiotic arrest by reducing IME1 expression and activating the BUB2-dependent branch of the spindle checkpoint. Genetics 164: 1333-1344.

HERMAN, P.K. and RINE, J. (1997). Yeast spore germination: a requirement for Ras protein activity during re-entry into the cell cycle. Embo $J$ 16: 6171-6181.

HERSKOWITZ, I., RINE, J. and STRATHERN, J.N. (1992). Mating-type determination and mating-type interconversion in Saccharomyces cerevisiae. In The molecular and cellular biology of the yeast Saccharomyces: gene expression, vol. 2 (ed. Jones, E. W. Pringle, J. R. and Broach, J. R.). Cold Spring Harbor Laboratory Press, New York, pp. 583-656.

HONGAY, C.F., GRISAFI, P.L., GALITSKI, T. and FINK, G.R. (2006). Antisense transcription controls cell fate in Saccharomyces cerevisiae. Cell 127: 735-745.

INAI, T., YUKAWA, M. and TSUCHIYA, E. (2007). Interplay between chromatin and trans-acting factors on the IME2 promoter upon induction of the gene at the onset of meiosis. Mol Cell Biol 27: 1254-1263.

JAYARAMAIAH RAJA, S. and RENKAWITZ-POHL, R. (2005). Replacement by Drosophila melanogaster protamines and Mst77F of histones during chromatin condensation in late spermatids and role of sesame in the removal of these proteins from the male pronucleus. Mol Cell Biol 25: 6165-6177.

JOSEPH-STRAUSS, D., ZENVIRTH, D., SIMCHEN, G. and BARKAI, N. (2007).
Spore germination in Saccharomyces cerevisiae: Global gene expression patterns and cell cycle landmarks. Genome Biol 8: R241.

KADOSH, D. and STRUHL, K. (1997). Repression by Ume6 involves recruitment of a complex containing Sin3 corepressor and Rpd3 histone deacetylase to target promoters. Cell 89: 365-371.

KASSIR, Y., ADIR, N., BOGER-NADJAR, E., RAVIV, N.G., RUBIN-BEJERANO, I., SAGEE, S. and SHENHAR, G. (2003). Transcriptional regulation of meiosis in budding yeast. Int Rev Cytol 224: 111-171.

KASSIR, Y. and SIMCHEN, G. (1976). Regulation of mating and meiosis in yeast by the mating-type region. Genetics 82: 187-206.

KRISHNAMOORTHY, T., CHEN, X., GOVIN, J., CHEUNG, W.L., DORSEY, J., SCHINDLER, K., WINTER, E., ALLIS, C.D., GUACCI, V., KHOCHBIN, S. et al. (2006). Phosphorylation of histone H4 Ser1 regulates sporulation in yeast and is conserved in fly and mouse spermatogenesis. Genes Dev 20: 2580-2592.

KUPIEC, M., BYERS, B., ESPOSITO, R.E. and MITCHELL, A.P. (1997). Meiosis and sporulation in Saccharomyces cerevisiae. In The molecular and cellular biology of the yeast Saccharomyces: Cell cycle and cell biology, vol. 3 (ed. Pringle, J. R. Broach, J. R. and Jones, E. W.). Cold Spring Harbor Laboratory Press, New York, pp. 889-1036.

LI, B., CAREY, M. and WORKMAN, J.L. (2007). The role of chromatin during transcription. Cell 128: 707-719.

MACDONALD, N., WELBURN, J.P., NOBLE, M.E., NGUYEN, A., YAFFE, M.B., CLYNES, D., MOGGS, J.G., ORPHANIDES, G., THOMSON, S., EDMUNDS, J.W. et al. (2005). Molecular basis for the recognition of phosphorylated and phosphoacetylated histone h3 by 14-3-3. Mol Cell 20: 199-211.

MALAVE, T.M. and DENT, S.Y. (2006). Transcriptional repression by Tup1Ssn6.'Biochem Cell Biol 84: 437-443.

MALLORY, M.J., COOPER, K.F. and STRICH, R. (2007). Meiosis-specific destruction of the Ume6p repressor by the Cdc20-directed APC/C. Mol Cell 27: 951961.

MARSTON, A.L. and AMON, A. (2004). Meiosis: cell-cycle controls shuffle and deal. Nat Rev Mol Cell Biol 5: 983-997.

MARTINEZ, M.J., ROY, S., ARCHULETTA, A.B., WENTZELL, P.D., ANNAARRIOLA, S.S., RODRIGUEZ, A.L., ARAGON, A.D., QUINONES, G.A., ALLEN, C. and WERNER-WASHBURNE, M. (2004). Genomic analysis of stationaryphase and exit in Saccharomyces cerevisiae: gene expression and identification of novel essential genes. Mol Biol Cell 15: 5295-5305.

MATSUMOTO, K., UNO, I. and ISHIKAWA, T. (1983). Initiation of meiosis in yeast mutants defective in adenylate cyclase and cyclic AMP-dependent protein kinase. Cell 32: 417-423.

MCCORD, R., PIERCE, M., XIE, J., WONKATAL, S., MICKEL, C. and VERSHON, A.K. (2003). Rfm1, a novel tethering factor required to recruit the Hst1 histone deacetylase for repression of middle sporulation genes. Mol Cell Biol 23: 20092016.

MIZUNO, T., NAKAZAWA, N., REMGSAMRARN, P., KUNOH, T., OSHIMA, Y. and HARASHIMA, S. (1998). The Tup1-Ssn6 general repressor is involved in repression of IME1 encoding a transcriptional activator of meiosis in Saccharomyces cerevisiae. Curr Genet 33: 239-247.

NEIMAN, A.M. (2005). Ascospore formation in the yeast Saccharomyces cerevisiae. Microbiol Mol Biol Rev 69: 565-584.

NORRIS, D. and OSLEY, M.A. (1987). The two gene pairs encoding H2A and H2B play different roles in the Saccharomyces cerevisiae life cycle. Mol Cell Biol 7: 3473-3481.

PIERCE, M., BENJAMIN, K.R., MONTANO, S.P., GEORGIADIS, M.M., WINTER, E. and VERSHON, A.K. (2003). Sum1 and Ndt80 proteins compete for binding to middle sporulation element sequences that control meiotic gene expression. Mol Cell Biol 23: 4814-4825.

PRIMIG, M., WILLIAMS, R.M., WINZELER, E.A., TEVZADZE, G.G., CONWAY, A.R., HWANG, S.Y., DAVIS, R.W. and ESPOSITO, R.E. (2000). The core meiotic transcriptome in budding yeasts. £Nat Genet 26: 415-423.

RADONJIC, M., ANDRAU, J.C., LIJNZAAD, P., KEMMEREN, P., KOCKELKORN, T.T., VAN LEENEN, D., VAN BERKUM, N.L. and HOLSTEGE, F.C. (2005). Genome-wide analyses reveal RNA polymerase II located upstream of genes poised for rapid response upon S. cerevisiae stationary phase exit. Mol Cell 18: 171-183.

RAISNER, R.M., HARTLEY, P.D., MENEGHINI, M.D., BAO, M.Z., LIU, C.L., 
SCHREIBER, S.L., RANDO, O.J. and MADHANI, H.D. (2005). Histone variant H2A.Z marks the 5 ' ends of both active and inactive genes in euchromatin. Cell 123: 233-248.

RATHKE, C., BAARENDS, W.M., JAYARAMAIAH-RAJA, S., BARTKUHN, M., RENKAWITZ, R. and RENKAWITZ-POHL, R. (2007). Transition from a nucleosome-based to a protamine-based chromatin configuration during spermiogenesis in Drosophila. J Cell Sci 120: 1689-1700.

RUTHENBURG, A.J., LI, H., PATEL, D.J. and ALLIS, C.D. (2007). Multivalent engagement of chromatin modifications by linked binding modules. Nat Rev Mol Cell Biol 8: 983-994.

SAGEE, S., SHERMAN, A., SHENHAR, G., ROBZYK, K., BEN-DOY, N., SIMCHEN, G. and KASSIR, Y. (1998). Multiple and distinct activation and repression sequences mediate the regulated transcription of IME1, a transcriptional activator of meiosis-specific genes in Saccharomyces cerevisiae. Mol Cell Biol 18: 1985-1995

SAMANTA, M.P., TONGPRASIT, W., SETHI, H., CHIN, C.S. and STOLC, V. (2006). Global identification of noncoding RNAs in Saccharomyces cerevisiae by modulating an essential RNA processing pathway. Proc Natl Acad Sci U S A 103: 4192-4197.

SCHALCH, T., DUDA, S., SARGENT, D.F. and RICHMOND, T.J. (2005). X-ray structure of a tetranucleosome and its implications for the chromatin fibre. Nature 436: 138-141.

SHIMIZU, M., LI, W., COVITZ, P.A., HARA, M., SHINDO, H. and MITCHELL, A.P. (1998). Genomic footprinting of the yeast zinc finger protein Rme1p and its roles in repression of the meiotic activator IME1. Nucleic Acids Res 26: 2329-2336.

SHIMIZU, M., LI, W., SHINDO, H. and MITCHELL, A.P. (1997). Transcriptional repression at a distance through exclusion of activator binding in vivo. Proc Natl Acad Sci U S A 94: 790-795.
SHOGREN-KNAAK, M., ISHII, H., SUN, J.M., PAZIN, M.J., DAVIE, J.R. and PETERSON, C.L. (2006). Histone H4-K16 acetylation controls chromatin structure and protein interactions. Science 311: 844-847.

SIMCHEN, G., PINON, R. and SALTS, Y. (1972). Sporulation in Saccharomyces cerevisiae: premeiotic DNA synthesis, readiness and commitment. Exp Cell Res 75: 207-218.

SINGH, S.R., PILLAI, B., BALAKRISHNAN, B., NAOREM, A. and SADHALE, P.P. (2007). Relative levels of RNA polll subunits differentially affect starvation response in budding yeast. Biochem Biophys Res Commun 356: 266-272.

STRICH, R., SUROSKY, R.T., STEBER, C., DUBOIS, E., MESSENGUY, F. and ESPOSITO, R.E. (1994). UME6 is a key regulator of nitrogen repression and meiotic development. Genes Dev 8: 796-810.

TSUI, K., SIMON, L. and NORRIS, D. (1997). Progression into the first meiotic division is sensitive to histone H2A-H2B dimer concentration in Saccharomyces cerevisiae. Genetics 145: 647-659.

VARMA, A., FREESE, E.B. and FREESE, E. (1985). Partial deprivation of GTP initiates meiosis and sporulation in Saccharomyces cerevisiae.'Mol Gen Genet 201: 1-6.

XIE, J., PIERCE, M., GAILUS-DURNER, V., WAGNER, M., WINTER, E. and VERSHON, A.K. (1999). Sum1 and Hst1 repress middle sporulation-specific gene expression during mitosis in Saccharomyces cerevisiae. Embo J 18: 6448-6454.

ZARAGOZA, O. and GANCEDO, J.M. (2000).'Pseudohyphal growth is induced in Saccharomyces cerevisiae by a combination of stress and CAMP signalling. Antonie Van Leeuwenhoek 78: 187-194.

ZHANG, H., ROBERTS, D.N. and CAIRNS, B.R. (2005). Genome-wide dynamics of $\mathrm{Htz} 1$, a histone $\mathrm{H} 2 \mathrm{~A}$ variant that poises repressed/basal promoters for activation through histone loss. Cell 123: 219-231. 


\section{Further Related Reading, published previously in the Int. J. Dev. Biol.}

See our Special Issue Fertilization edited by Paul M. Wassarman and Victor D. Vacquier at: http://www.ijdb.ehu.es/web/contents.php?vol=52\&issue=5-6

See our Special Issue Plant Development edited by José Luis Micol and Miguel Angel Blázquez at: http://www.ijdb.ehu.es/web/contents.php?vol=49\&issue=5-6

Chromatin remodeling in plant development

José A. Jarillo, Manuel Piñeiro, Pilar Cubas and José M. Martínez-Zapater

Int. J. Dev. Biol. (2009) 53 doi: 10.1387/ijdb.072460jj

Dynamic alterations of linker histone variants during development

James S. Godde and Kiyoe Ura

Int. J. Dev. Biol. (2009) 53 doi: 10.1387/ijdb.082644jg

The role of ion fluxes in polarized cell growth and morphogenesis: the pollen tube as an experimental paradigm

Erwan Michard, Filipa Alves and José A. Feijó

Int. J. Dev. Biol. (2009) 53 doi: 10.1387/ijdb.072296em

A histone $\mathrm{H} 1$ variant is required for erythrocyte maturation in medaka Osamu Matsuoka, Norihisa Shindo, Daisuke Arai and Toru Higashinakagawa Int. J. Dev. Biol. (2008) 52: 887-892

Control of reproduction by Polycomb Group complexes in animals and plants Anne-Elisabeth Guitton and Frederic Berger

Int. J. Dev. Biol. (2005) 49: 707-716

Expression of DjXnp, a novel member of the SNF2-like ATP-dependent chromatin remodelling genes, in intact and regenerating planarians.

Leonardo Rossi, Paolo Deri, Ilaria Andreoli, Vittorio Gremigni, Alessandra Salvetti and Renata Batistoni

Int. J. Dev. Biol. (2003) 47: 293-298

New telomere formation during the process of chromatin diminution in Ascaris suum. Stephan Jentsch, Heinz Tobler and Fritz Müller

Int. J. Dev. Biol. (2002) 46: 143-148

Extensive conservation of sequences and chromatin structures in the bxd polycomb response element among Drosophilid species.

Gaetano I Dellino, Christophe Tatout and Vincenzo Pirrotta

Int. J. Dev. Biol. (2002) 46: 133-141

Methylation and chromatin conformation in the U2af1-rs1 imprinted gene in the male germ cell line

MM Zalduendo, D Boyano, R Feil, N Andollo, J Arechaga

Int. J. Dev. Biol. (2001) 45: S145-S146

Characterisation of developmentally regulated chromatin structure in the coding region of the proto-oncogene, c-fos, in the male laboratory mouse.

C Kanduri and R Raman

Int. J. Dev. Biol. (1999) 43: 279-282

Interphase-like chromatin configuration induced by cycloheximide in maturing pig oocytes: effects of protein phosphatase inhibitors.

J Rozinek, J Petr, R Grocholová and F Jílek

Int. J. Dev. Biol. (1996) 40: 1171-117

X-chromosome activity: impact of imprinting and chromatin structure.

R V Jamieson, P P Tam and M Gardiner-Garden

Int. J. Dev. Biol. (1996) 40: 1065-1080

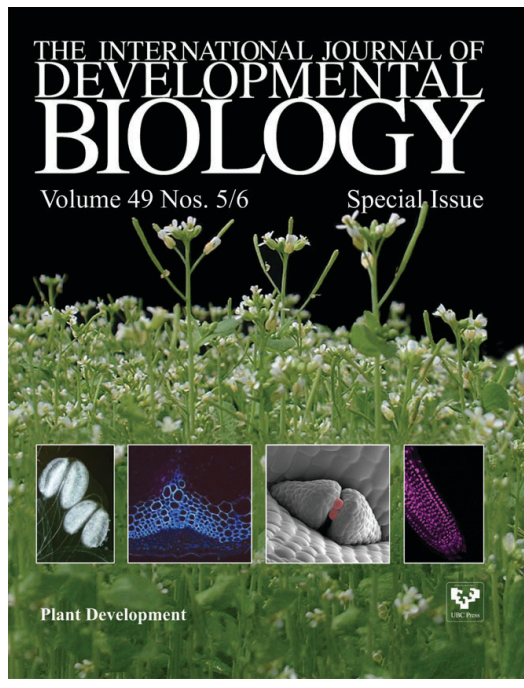

2006 ISI **Impact Factor $=3.577^{* *}$

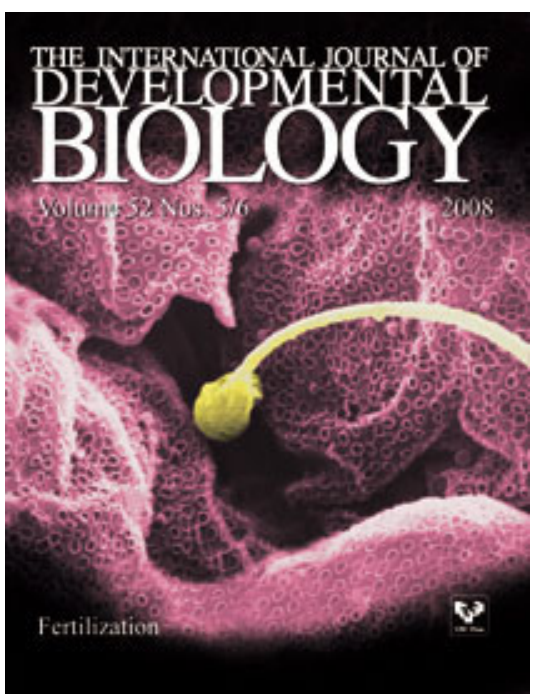

